\title{
O lugar da experiment-ação no trabalho clínico em Gestalt-terapia
}

\section{Experiment-action in Gestalt-therapy clinical work}

\author{
Mônica Botelho Alvim* \\ Professora Adjunta no Instituto de Psicologia da Universidade Federal do Rio de \\ Janeiro/UFRJ - Rio de Janeiro, RJ, Brasil \\ Professora no curso de especialização em Gestalt-Terapia do Instituto de Gestalt- \\ terapia de Brasília - Brasília, DF, Brasil
}

Jorge Ponciano Ribeiro**

Professor Emérito da Universidade de Brasília/UnB - Brasília, DF, Brasil

\begin{abstract}
Resumo
A proposta metodológica central da Gestalt-terapia foi construída em torno de uma perspectiva que toma como foco a experiência humana no mundo. No artigo ampliamos o significado do trabalho gestáltico com a experiência frequentemente reduzido ao uso do experimento como técnica - abordando suas origens fenomenológicas e dialogando com Merleau-Ponty, propondo conceber a psicoterapia como campo de presença. A existência se dá no campo organismo-ambiente e a experiência é uma estrutura configurada a partir dessa situação relacional no mundo. Partindo do id da situação, a psicoterapia visa à ampliação da experiência do cliente no aqui-agora do encontro terapêutico para significar sua ação espontânea e criativa no mundo. O processo de contato implica um mergulho no mundo ambíguo da experiência com o outro, gerando oportunidade de um exercício criativo envolvido com uma capacidade humana de agredir, transformar e instituir. Consideramos a experiment-ação na Gestalt-terapia meio para que a ação espontânea e criativa se desvele, produzindo significados e transgredindo o instituído.
\end{abstract}

Palavras-chave: Fenomenologia, Gestalt-terapia, Merleau-Ponty, Corpo, Psicoterapia.

\begin{abstract}
Gestalt-Therapy main methodological proposal was built from a perspective that focuses human experience in the world. In this article we seek to amplify the meaning of working with experience - many times reduced to use an experiment as a technique. We discuss gestalt therapy phenomenological roots and make a dialogue with Merleau-Ponty, conceiving psychotherapy as a presence field. Human existence flows in organismenvironment field and experience is considered a structure configured from this relational situation in the world. Starting from situation's id,
\end{abstract}


psychotherapy intends to amplify client's experience here and now, in the therapeutic encounter to signify his creative and spontaneous action. Contact process results in a dive in the ambiguous world of experience-withother, and this is an opportunity to make a creation exercise which is involved with human aggression capacity that allows him to transform and institute culture. We consider gestalt-therapy experiment-action a mean to unfold spontaneous and creative action, producing meanings and transgressing culture.

Keywords: Phenomenology, Gestalt-therapy, Merleau-Ponty, Body, Psychotherapy.

O Ser é o que exige de nós criação para que dela tenhamos experiência Merleau-Ponty

A Gestalt-terapia, que emergiu nos anos 50 e 60, com foco no experimento e na ação criativa, propunha trazer o sensível e o corpo para o setting terapêutico, indicando que a experiência era um importante referencial. O grupo que pensou e propôs a Gestaltterapia teve o nome Terapia experiencial como uma das mais fortes propostas para a nova abordagem. A conhecida afirmação atribuída a Fritz Perls, seu fundador, é emblemática: "perca a razão, recupere os sentidos".

Se tal afirmação, por um lado, reflete o clima de contracultura vivido por Perls nos anos 60, por outro, aponta para a proposta fenomenológica de retorno ao mundo da experiência sensível. Nos últimos anos a influência da fenomenologia tem se tornado cada vez mais explícita, pelo menos para uma parte dos gestalt-terapeutas, e a noção de campo que se desenvolveu como base para o trabalho psicoterápico pode nos auxiliar a ampliar o significado dessa proposta.

O que desejamos frisar aqui é que a proposta de uma psicoterapia que trabalha com a experiência se deturpa quando esse sentido fenomenológico de experimentar - ação expressa por um verbo - se reduz a experimento como técnica ou coisa, expressa por um substantivo. O que não significa dizer que um experimento não possa ser utilizado como recurso para o trabalho com a experiência. Tampouco que os mal entendidos acerca dos experimentos em Gestalt-terapia justifiquem uma postura de alijar o trabalho com a experiência.

Neste artigo, discutimos o caráter de experimentação do trabalho psicoterápico em Gestalt-terapia, buscando ampliar seu significado e discutir seus fundamentos fenomenológicos, dialogando com alguns pontos da obra de Merleau-Ponty.

Consideramos que 0 ato psicoterápico inaugurado pela Gestaltterapia - centrado na experiência - explicita seu caráter 
fenomenológico, ao mesmo tempo em que revela um fundo enredado com a arte, que dirige seu olhar sobre o fenômeno humano, atravessado por referenciais estéticos (ALVIM, 2007a; ALVIM, 2007b). Ao se basear na experimentação, fazendo uma passagem da explicação para a experiência, a Gestalt-terapia permite que 0 ato psicoterápico seja um campo de experiência. Como propôs MerleauPonty em sua ontologia do Ser, convida a psicoterapia a mergulhar na natural ambigüidade do mundo, para ressignificar a existência.

Desde a proposta que traz o livro Ego, fome e agressão (PERLS, 1942/2002), podemos encontrar indícios da escolha de Fritz e Laura Perls por referenciais fenomenológicos. Tal proposta envolve uma dupla passagem. Em primeiro lugar deixar um referencial que se orientava por um mecanismo causa e efeito, implícito em um modelo associacionista, para assumir outro, aquele de uma psicologia descritiva interessada na forma ou configuração. Em segundo lugar, a passagem de um paradigma que preconizava o intrapsíquico para outro que tinha como centro a noção de organismo ou campo.

A busca de substituir a psicologia da associação pela psicologia da gestalt e o conceito psicológico por um conceito organísmico (BORIS, apud PERLS, 2002) reflete uma mudança paradigmática que os Perls introduzem na nova abordagem proposta. Tal mudança é fruto de seu contato com um viés de pensamento que tem raízes na psicologia proposta por Brentano e um posterior desenvolvimento pela fenomenologia husserliana. O contato da Gestalt-terapia com esse viés de pensamento se dá por meio da primeira e segunda geração de psicólogos da gestalt, como indicado por Laura Perls (1992, p.150): "para o desenvolvimento da Gestalt-terapia os trabalhos de Wertheimer, Goldstein e Lewin tornaram-se particularmente importantes". Esses autores inspiraram a proposta perlsiana de fazer uma transposição do modelo associacionista para o modelo gestáltico (oferecido pela psicologia da forma) e da visão intrapsíquica para a de campo ou organísmica. Ambos privilegiaram em seus trabalhos a noção de campo organísmico quando realizaram pesquisas que permitiram reconhecer, no domínio das relações comportamentais (LEWIN, 1973) ou da fisiologia organísmica em sua relação com o meio (GOLDSTEIN, 2000), a vigência de um campo, senão transcendental ao menos concebido em termos muito próximos daquilo que Husserl chamava de ego transcendental. É nessas formulações, precisamente, que F. Perls encontraria os indícios que o levariam a propor um retorno à fenomenologia (GRANZOTTO, 2005, p.45).

A autora ressalta nessa passagem a ênfase fenomenológica na gênese da Gestalt-terapia, tema central de sua pesquisa (PERLS, 1992, p. 150).

Os paradigmas organísmico e holístico, que, de modo amplo, consideram homem e ambiente uma unidade orgânica e postulam a 
existência de uma capacidade ativa do organismo na direção da autoregulação, capitaneiam a "revisão da psicanálise" proposta por Perls no livro Ego, fome e agressão, que traz a intenção de reorientá-la para um ponto de vista organísmico.

Paul Goodman, cerca de dez anos mais tarde, ao reunir-se a Fritz e Laura Perls, encontrou nas idéias de Ego, fome e agressão uma grande familiaridade com sua própria formação filosófica. Seu encontro foi fértil e ao ser convidado por Fritz para redigir uma parte do livro Gestalt-terapia, agregou algumas de suas idéias, provenientes de sua leitura de Husserl e Dewey. Declarou, em carta a Kurt Koffka, quando da discussão acerca do nome "Gestalt-terapia", conhecer a fenomenologia husserliana a partir da obra Idéias e tê-la tomado como um dos referenciais de suas formulações no livro Gestalt-terapia (STOHER, 1999, p.80). A Gestalt-terapia que se consolida depois de 1951 tem um corpo teórico estruturado em torno da visão organísmica, expresso nas noções de campo organismoambiente e fronteira de contato, ajustamento criativo e agressão. Traz como proposta de método psicoterápico o trabalho com a experiência imediata, foco deste artigo.

No livro Ego, fome e agressão, Perls já propunha, como discutimos em trabalho anterior (ALVIM, 2007b), um ego insubstancial, como uma função de contatar o presente. No livro Gestalt-terapia, o processo de ajustamento criativo é descrito como um processo eminentemente temporal e tem uma grande familiaridade com a descrição fenomenológica da vivência do tempo (PERLS et al., 1997). Isso reflete uma ênfase na experiência no mundo, no a priori da correlação sujeito-objeto. Esse fundo está presente na Gestaltterapia. Está expresso na noção de campo organismo-ambiente: há uma estrutura da experiência, que é a unidade figura-fundo formada por organismo e ambiente a partir do campo. O tema da psicologia é definido como o estudo da operação da fronteira de contato no campo organismo-ambiente, o que indica o foco na experiência. Está expresso na noção de ajustamento criativo: a experiência é essencialmente contato, o funcionamento humano normal é a capacidade humana de fazer ajustamentos criativos quando em interação no campo organismo-ambiente. Também está expresso na proposta de psicoterapia que Perls, Hefferline e Goodman (1997, p.46) introduzem quando definem a tarefa principal da Gestaltterapia como aquela de "trabalhar a unidade e a desunidade dessa estrutura da experiência aqui e agora". A noção de aqui-agora aponta para as idéias de atualidade e apresentação, referindo-se a um campo de presença no sentido fenomenológico.

A obra de Merleau-Ponty dialoga permanentemente com 0 pensamento psicológico e nos oferece uma compreensão epistemológica aprofundada da psicologia. Entretanto não há influências do trabalho de Merleau-Ponty na Gestalt-terapia; a 
influência fenomenológica que ela tem provém, como discutimos, da fenomenologia husserliana, principalmente pela via da Psicologia da Gestalt e Teoria Organísmica de Goldstein, mesma tradição na qual se referencia Merleau-Ponty, o que nos oferece a possibilidade do diálogo. Os dois pensamentos são gerados na primeira metade do século XX e eclodem nas décadas de 50 e 60, quando se configurou com força uma sociedade industrial, tecnocrática e baseada no cientificismo. Constituem-se em reações a uma espécie de distanciamento do mundo ditado pelo pensamento predominante naquela sociedade racionalista, mecanicista e dualista. Propuseram um retorno ao mundo da experiência para resgatar a origem, a fé perceptiva, inspirados - direta ou indiretamente, em maior ou em menor grau - na fenomenologia. Merleau-Ponty parte da obra de Husserl e trabalha no desenvolvimento daquilo que chamou de impensado na obra do filósofo, acentuando a necessidade de buscar, no mundo da experiência, a origem, o a priori da correlação sujeitoobjeto. Esse a priori está na experiência em estado bruto, o momento no qual há uma com-fusão do sujeito com o objeto, no próprio ato, antes da cisão que a reflexão provoca.

Merleau-Ponty desenvolve a noção de estrutura do comportamento, que conota o comportamento como totalidade organísmica, forma em processo. A percepção - um campo que integra consciência e mundo - gera os significados que dirigem a situação. Na Fenomenologia da Percepção aprofunda a temática das relações homem-mundo e desenvolve o tema da temporalidade da consciência, que já havia sido anunciado na noção de estrutura, onde o filosofo discute a ordem humana e a noção de virtualidade. Assume o corpo como experiência vivida e temporal. Quando caminha para uma ontologia do Ser Bruto, Merleau-Ponty enfatiza a correlação sujeito-objeto, destacando o caráter ambíguo da relação - desde o início considerada dialética - entre pessoa e mundo. Tal ambigüidade envolve a noção de Ser Bruto como totalidade homem-mundo. Ao mesmo tempo em que é indivisível, pois que representa a correlação sujeito-objeto, envolve diferentes dimensões, como faces de uma mesma moeda, uma dimensão invisível e outra visível, que se revezam no tempo, em mim e no outro. O Ser Bruto, o ponto originário de encontro entre sujeito e objeto, de onde parte tudo, onde tudo se passa, consiste, portanto, em um campo de presença, temporal, centralizado, aquiagora, na experiência imediata. Esta experiência é compreendida como uma síntese que engloba eu e mundo, eu e outro, passado, presente e futuro. Um fundo cultural invisível, significações vividas expressas na forma do gesto corporal - movimento ou palavra - que dialogam com o visível e com ele se revezam.

\section{A Gestalt-terapia proposta por Perls, Hefferline e Goodman}


Perls, Hefferline e Goodman (1951, p. 46) definem como tarefa principal da Gestalt-terapia "trabalhar a unidade e a desunidade dessa estrutura da experiência aqui e agora". Consideramos que essa tarefa indica o foco na experiência que tem a Gestalt-terapia: experimentar a ação no campo aqui-agora e trabalhar com aquilo que ela expressa. A estrutura da experiência é uma unidade figura-fundo, forma, configuração ou gestalt, constituída por organismo e ambiente a partir do campo, processo dinâmico, aqui e agora, que tem um sentido de temporalidade, ou seja, é atualidade e apresentação no sentido fenomenológico. O interesse da terapia está focado na experiência vivida agora (como presença, ou seja, como aquilo que se apresenta) aqui (nesta situação, neste campo). Esta experiência vivida aqui-agora tem uma estrutura, forma ou configuração - que emana do campo - e que expressa o seu significado. Nossa atenção é para a forma (estrutura da experiência aqui-agora), buscando o significado da experiência nessa relação que me envolve (terapeuta) e ao cliente.

Essa unidade figura-fundo pode, momentaneamente, estar perturbada, ser uma "desunidade", forma sem vigor, força ou brilho. O trabalho psicoterápico busca refazer as relações dinâmicas da figura-fundo até que se forme uma gestalt vigorosa, expressando que: o contato se intensificou, há awareness e o movimento ou comportamento presente está energizado. "A realização de uma gestalt vigorosa é a própria cura, porquanto a figura de contato não é apenas uma indicação da integração criativa da experiência, mas é a própria integração" (PERLS; HEFFERLINE; GOODMAN, 1997, p.46).

Isso indica que o contexto psicoterápico trabalha com uma ação que visa possibilitar a integração criativa da experiência, transformando uma gestalt débil, um estado de desintegração necessidade-figurafundo, em uma experiência integradora que deriva do trabalho criador na situação psicoterápica. A criação em si não é o foco da Gestalt-terapia, mas sim o ato de criação. De acordo com Perls, Hefferline e Goodman (1997, p. 212) o momento criativo é a intuição do todo e prefigura o produto final, mas é o manuseio do meio que revela na prática sua intenção e o força a percebê-la. Essa idéia revela a importância que é dada à ação aqui-agora como uma forma de produzir um conhecimento acerca de si próprio (em relação), focado em como alguém age e faz contato na situação atual para que se passe, deste ponto, a uma ação criativa que integre a necessidade atual do campo.

Nessa direção, Merleau-Ponty (1975) afirma que a consciência não é a posse de um juízo, mas uma rede de intenções significativas, antes vividas que conhecidas, ou seja, que envolve aquilo que se apresenta na experiência e não as representações, já "prontas". De acordo com ele, essa rede de intenções está ligada à ação, animada por uma 
intenção prática que não é finalista. Propõe analisar o sentido imanente da ação e sua estrutura intencional própria, já que a ação revela um estilo próprio, está matizada por uma singularidade.

A ação, para ele, é dada por um engajamento corporal. O corpo produz uma síntese na percepção, que conduz ao novo - criação -, a partir de uma experiência motora - Praktognosia. Isso quer dizer que através de uma práxis produz-se uma gnose - conhecimento do significado, que se expressa na forma motora, na ação motora no campo.

Experimentar é uma oportunidade de realização de uma ação que, em curso, pode ser vivida e experimentada, fazendo brotar um sentido de self a partir da awareness de si próprio no campo. Esta é uma força de integração porque é criativa. Perls, Hefferline e Goodman (1997, p. 62). Afirmam a esse respeito:

O terapeuta conta com a awareness de si próprio para lidar com o paciente, de acordo com a situação, dando a ele a oportunidade de exercer suas agressões (ou o que quer que seja) em circunstâncias reais e enfrentar uma reação normal sem que o teto desabe. Assim, aquilo que é não-consciente pode surgir em primeiro plano de modo que sua estrutura possa ser experienciada. Ajudamos o paciente a ver como ele censura, retrai-se, com quais músculos, imagens, recursos. Quando ele percebe-se reprimindo ativamente ele mesmo pode começar a relaxar a repressão.

A psicoterapia gestáltica é o método da awareness criativa e tem como objetivo concentrar-se na estrutura da situação concreta; preservar a integridade da concretude, encontrando a relação intrínseca entre fatores socioculturais, animais e físicos; e experimentar e promover o poder criativo do paciente de reintegrar as partes dissociadas.

A terapia consiste em analisar a estrutura interna da experiência concreta, qualquer que seja o grau de contato desta: não tanto o que está sendo experienciado, relembrado, feito, dito, etc., mas a maneira como está sendo feito, experienciado, relembrado, dito. (PERLS; HEFFERLINE; GOODMAN, 1997, p.46).

O recurso primordial do Gestalt-terapeuta é a recomendação destacada em seu mapa teórico - de procurar o como ao invés do porquê, preceito que faz alusão a como se dá a experiência da pessoa diante de mim, terapeuta. Isso não é apenas um recurso técnico, mas uma posição baseada na premissa organísmica de que a forma é significação e expressa a estrutura mais espontânea do campo. Assim, aquela forma que se configura expressa aquilo que predomina na experiência atual. Malevitch e os artistas abstracionistas buscaram a forma geométrica para alcançar a sensibilidade perdida na arte representativa e mimética, para fugir da figuração, da imitação do objeto que, já conhecido e familiar, Ihes fazia perder a possibilidade de contato com a experiência sensível, aquela que acontece diante do 
novo. Pensamos que atentar para a forma da experiência do cliente liberta o olhar dos conceitos. Tentar acompanhar o raciocínio do cliente, a construção racional, as explicações que ele constrói em seu discurso convida a racionalidade do terapeuta. Tais construções representações que emanam quando o self funciona na modalidade personalidade - podem ser comparadas por analogia aos objetos dos quais os artistas abstracionistas tentavam se desprender.

Atentar para a forma significa se conectar com as qualidades estéticas presentes na experiência vivida com a pessoa, um trabalho que visa essencialmente à experiência do campo. Miller afirma, na introdução ao livro Gestalt-terapia (PERLS; HEFFERLINE; GOODMAN, 1997, p.25)

A Gestalt-terapia argumenta que é precisamente na fronteira de contato, o local de encontros entre self e outro e de afastamento para ambos, que a psicologia pode explicar melhor, e os psicoterapeutas presenciar melhor e reportar aos pacientes a responsabilidade que as pessoas têm de moldar sua própria experiência.

Nesse sentido, o autor nos convida a pensar na psicoterapia como uma experiência relacional, no encontro e no afastamento entre self e outro.

O trabalho de campo na Gestalt-terapia, buscando a relação em ação, a experiência, a apresentação, em vez do "falar sobre" da representação, faz o mesmo que a arte. Retorna à origem, à percepção de terapeuta e cliente tomando forma. A terapia trabalha com essa unidade que se configura, do modo como ela se configura.

Lembramos que o contato ou ajustamento criativo parte do campo, emerge no encontro de organismo e ambiente. O campo é o fundo de onde ambos emergem como uma totalidade. Na terapia há um processo de contato acontecendo, um processo de ajustamento criativo que consiste na formação de uma figura a partir de um fundo que inclui terapeuta e cliente em situação. O processo de contato é um processo ativo de ajustamento criativo que se dá engajado na situação, na experiência com o outro na fronteira ou campo organismo-ambiente.

O self não tem consciência de si próprio abstratamente, mas como estando em contato com alguma coisa. Seu "Eu" é polar com relação a um "Tu" e a um "Isso". O Isso é a sensação dos materiais, dos anseios e do fundo; o Tu é o caráter direcionado do interesse; o Eu é tomar as providências e fazer as identificações e as alienações progressivas. (PERLS; HEFFERLINE; GOODMAN, 1997, p. 183).

Tal afirmação anuncia as "estruturas possíveis do self" (PERLS; HEFFERLINE; GOODMAN, 1997, p. 183) - Id, Ego e Personalidade enquanto etapas principais do ajustamento criativo. Tais etapas são uma seqüência de formação e destruição de figuras ou, dito de forma diferente, uma seqüência temporal de configurações ou estruturas nas quais o modo de funcionamento do self varia em níveis sensório, 
motor e categorial. Nesse sentido, o contato ou ajustamento criativo de organismo e ambiente é um processo de experiência que parte de uma novidade ou diferença que movimenta um excitamento ou interesse da situação, direcionando a ação criativa motora, com uma deliberação espontânea voltada para a manipulação da diferença, de modo que a novidade seja assimilada ou rejeitada.

A função id do self constitui-se no fundo cujo elemento principal é o corpo como um sistema perceptivo e proprioceptivo: desejos, necessidades, apetites, excitações orgânicas, situações inacabadas, dores, emoções, tudo que nos impulsiona em direção a alguma coisa, a um futuro imediato, sempre partindo da relação organismoambiente. Durante essa fase, predominam as sensações, há um estado preponderante de inconsciência e os sentimentos são incipientes. Não há um sentimento de eu individual e separado, há passividade, dispersão, a vivência está diluída no meio. É desse fundo indiferenciado de possibilidades que parte o apetite que direcionará a ação.

A função ego do self é uma função de deliberação que se inicia a partir da dominância de um interesse, quando o apetite que era vago escolhe uma possibilidade e há uma mobilização motora. O corpo está envolvido enquanto um sistema motor e o que predomina nessa fase é a ação: decidir, escolher, aceitar, rejeitar, agredir, transformar. As duas outras funções - id e personalidade - se expressam no contato pela função ego, que funciona identificando ou alienando e o critério para isso é o interesse que dirige a ação. Há uma consciência de eu aumentada, e essa autoconsciência é deliberada, de modo ativo, sensorialmente alerta e motoricamente agressiva [...]. A deliberação saudável é a restrição consciente de determinados interesses, percepções e movimentos para concentrar a atenção em outros (PERLS; HEFFERLINE; GOODMAN, 1997, p.185). Algumas limitações são feitas para que haja uma concentração da ação na tarefa escolhida, aquela que está a serviço do interesse dominante, o que gera uma sensação de estar ativo e de ser separado do ambiente, exercendo sobre a situação um domínio. Quanto maior a atividade, maior a sensação de domínio. Os sentidos estão "de prontidão" em um estado ativo. Na medida em que decresce a atividade, decresce a sensação de domínio, que se transforma em descoberta e invenção. É importante ressaltar que a função de deliberação aqui é consciente, mas não é racional. Quando há introspecção, teorização e racionalização, o ambiente não é mais um pólo, mas é sentido como algo externo, separado e o ego se transforma em uma estrutura dominante que dirige a situação pelo exercício da vontade, função pertencente à ordem da razão. Estamos aqui nos referindo a uma consciência como um corpo perceptivoprático que se dirige a um objetivo e aliena outros, a partir da situação. Nesse sentido a ação é espontânea, um todo que une 
sensação, movimento e emoção em relação à situação e tem como resultado a criação. O tipo de espontaneidade a qual nos referimos é descrita por Perls, Hefferline e Goodman (1997) como um modo intermediário, nem ativo nem passivo, expresso por um modo verbal não existente na língua portuguesa: o modo médio, que indica que o sujeito conduz a ação sem sobrepor-se, tampouco subjugar-se. Ao fazer referência a esse tipo de deliberação, utilizamos o termo "deliberação espontânea".

A função personalidade é uma função onde a figura é uma atividade categorial, formadora de conceitos a partir da experiência. É a face conhecida e facilmente visível do eu, uma vez que se constitui daquela parte da experiência que foi integrada e reconhecida e confere um núcleo de identidade a partir daquilo que alguém pensa que é, do conjunto de representações que pôde construir a partir de suas experiências. Aquilo que se transforma em representação foram estratégias eficazes para promover o equilíbrio em determinada situação. Em situações ideais de funcionamento espontâneo, as representações da personalidade seriam tomadas como fundo e reformadas a cada novo contato. No entanto, o que seria uma função muitas vezes termina por se constituir em um objeto - personalidade, nesse sentido definido no livro Gestalt-terapia: como "o sistema de atitudes adotadas nas relações interpessoais; é a admissão do que somos, que serve de fundamento pelo qual poderíamos explicar nosso comportamento" (PERLS; HEFFERLINE; GOODMAN, 1997, p.187). As atitudes retóricas, a moralidade e a lealdade social são os principais mecanismos de formação da personalidade.

Em síntese, o processo de ajustamento criativo descrito a partir das modalidades de função self toma como ponto de partida a função id, que se expressa na ação exercida pelo self na modalidade ego e que vai constituindo a função personalidade.

\section{Campo e situação}

A noção de campo organismo-ambiente indica a premissa gestáltica de que a existência se dá no mundo, premissa essa que orienta toda nossa proposta. Perls, Hefferline e Goodman, ao se referir ao contexto da psicoterapia, pouco utilizaram o termo campo, mas introduziram a palavra situação. Robine (2003b) ressalta esse aspecto para enfatizar a idéia de que criamos e somos criados pela situação. A situação terapêutica envolve terapeuta e cliente compondo um campo.

Antes mesmo que a construção de uma gestalt comece a se formar numa sessão de terapia, a situação começou a ser criada e será fundo de figuras que virão. É no vínculo com uma situação, qualquer 
que seja ela, que o self será levado a se desenvolver - ou não (ROBINE, 2003b, p.4).

Esse processo de desenvolvimento do self, tem um caráter de fluidez temporal. A novidade que se apresenta é atual e carregada de emoção e excitamento, dando a direção para a ação criativa que representará uma possível solução vindoura, ainda desconhecida. A ação motora envolvida na criação se alimenta da excitação e opera algo que vai se produzindo em ato e cujo resultado final é desconhecido.

De acordo com Perls, Hefferline e Goodman (1997) uma impressão de segurança é proporcionada pelo apego ao status quo, aos ajustamentos que obtivemos no passado e o novo excitamento pode ser uma ameaça a essa segurança. No entanto, não existe algo como uma segurança verdadeira, porque nesse caso o self seria uma fixidez. Os autores afirmam que quando não há um medo irracional, não surge o problema de estar ou não seguro, mas nos encarregamos do problema confrontando-o.

Onde o self tem força da qual se alimentar é onde justamente não há nenhuma sensação de segurança. Há talvez uma sensação de prontidão; a aceitação do excitamento, um certo otimismo bobo sobre a possibilidade de mudança da realidade, e uma lembrança habitual de que o organismo se regula a si mesmo e no fim não se desgasta ou explode (p.218).

Isso é referido por eles como uma espécie de fé, que consideramos estar implicada na situação, ou seja, é sentida com o outro, uma confiança construída a partir do contato. Merleau-Ponty (2000, p.23) desenvolve a noção de fé perceptiva, fazendo referência a uma dimensão de consciência que envolve "a certeza injustificável de um mundo sensível comum a todos nós".

No funcionamento neurótico há racionalização e perda dessa fé na situação, há fixação em um determinado modus operandi ou em uma representação. Há um distanciamento da situação que se apresenta e o processo de ajustamento criativo não se desenvolve, há reprodução e não criação. Nesse sentido,

a neurose, definida como perda do funcionamento do self que permite que as rotinas, a fisiologia secundária e o sistema de hábitos assegurem ajustamentos mínimos, pode ser vista como uma negação da situação (ROBINE, 2005, p.4).

Então, a terapia deve buscar afirmar a situação. Tornar-se aware da experiência imediata com o outro, em situação, é focar-se na situação aqui-agora. Miller (2002) considera o campo como uma emergência da situação, indicando a necessidade de ficar com a experiência presente. 
Atualmente a Gestalt-terapia tem se apoiado numa concepção de "campo que emerge" ao invés de começar com duas figuras ou papéis já bem definidos, chamados terapeuta e cliente, ainda que ambos já saibam o que vão fazer naquele encontro. Então devemos falar de "ficar com" o processo que se desvela, à medida que ele brota, se diferencia, se dilui e dá nascimento a diferenças novamente, e assim por diante. Agora nós tentamos começar mais inocente e indefinidamente, deixando que os eventos assumam suas próprias proporções, ainda que contribuindo para dar forma a eles (MILLER, 2002, p. 112).

\section{O id da situação}

Robine (2003b, 2003a) refere-se ao "id da situação", tema que sublinha em sua leitura do livro Gestalt-terapia, e que alude à função id do self. Ao tratar da psicoterapia, enfatiza que o id nasce da situação, ressaltando que é a situação - no sentido de um campo organismo-ambiente - que contém o id. Lembra que o paradigma de campo orienta a relação terapêutica para essa perspectiva.

Enquanto situação atual ela é encontro de diferenças e exige um trabalho de ajustamento criativo: a atividade motora exercida pelo self funcionando na modalidade ego é alimentada pelo id da situação; um sistema motor em atividade orientado por um sistema sensorial, em contato com o ambiente, manipulando e criando.

$O$ ato do self é uma seqüência de etapas que se dão no presente como uma passagem do passado em direção ao futuro, em contato com o mundo. Não prescinde do corpo, é corporeidade, sensação e movimento. O corpo faz uma síntese temporal-espacial enquanto um corpo-presença, engajado na situação - no sentido de que não se tem uma sensação dividida entre si próprio e coisa, o que há é a "experiência da situação" (PERLS; HEFFERLINE; GOODMAN, 1997, p.183).

O paradigma do campo organismo/ambiente postula a anterioridade da indiferenciação da experiência do Eu e do Tu: "A experiência é anterior ao 'organismo' e ao 'ambiente', que são abstrações da experiência" [ele afirma, citando Perls, Hefferline e Goodman, 1951/1997]. É daí que partimos para conhecer o trabalho que se opera no encontro terapêutico (ROBINE, 2003a, p.24).

O trabalho de ajustamento criativo na situação terapêutica busca a awareness da função id, aquilo que puxa e movimenta e que é anterior ao ego (ROBINE, 2003a). A ação motora no campo, que se dá na fase do contato, quando o self funciona na modalidade ego, parte de um fundo - o id da situação - no trabalho de ajustamento criativo. 
O trabalho de awareness a partir da função id envolve a atenção à forma, provém dos sentidos, do corpo, da fala espontânea, enfim, é intencionalidade operante, atividade pré-reflexiva com um sentido bruto, não refletido.

É isso que marca a diferença entre orientar-se pela necessidade atual - que emana do campo e que é sinalizada pelos sentidos quando o self funciona na modalidade id - ou pela representação que o cliente tem dele mesmo - personalidade. Quando o cliente tende a atuar na relação com o terapeuta a partir da função personalidade, salta, no encontro terapêutico, a fase id, o nascimento do sentido e a possibilidade da criação e da novidade.

É nesse sentido que a intervenção psicoterápica toma como ponto de partida a awareness da função id - do fundo indiferenciado de possibilidades de onde brota 0 apetite dominante, figura. Esse elemento dominante é que direcionará a ação na psicoterapia.

A intervenção, na situação psicoterápica, é a escolha de uma trilha, um caminho. Pode ser feita pelo cliente. Quando ele está aware dessa dominância, ele mesmo marca essa trilha, convida o terapeuta e prossegue desbravando o sertão desconhecido. O terapeuta, que aceitou o convite, embarca, segue junto e por vezes dá indicações, mostra algo aqui e ali, uma curva, uma clareira, um atalho pequenas intervenções que movimentam a viagem, a seqüência de figuras e fundos.

A intervenção feita pelo terapeuta pode tomar diversas formas: 1) enunciar uma questão ou afirmação; 2) propor um experimento clássico - como por ex. a cadeira vazia -; 3) propor a utilização de recursos expressivos, como na arte terapia gestáltica; 4) manter o foco do trabalho na sensação e na awareness sensorial - o que pode ser conduzido com pequenos trabalhos corporais, respiração, movimentos, exercícios, relaxamento, ou apenas dirigindo a atenção para o corpo, sentimentos, sensações; 5) manter o foco na situação, ou seja, na relação com o terapeuta, o que envolve atentar-se para a ação em curso na interação, como exemplificado a seguir:

Cliente - "Não sei o que dizer." (leve rubor)

Terapeuta - "Como é para você estar aqui, diante de mim, e não saber o que dizer? Como você se sente?"

O terapeuta, atento sensivelmente à forma que se apresenta, nota uma gestalt débil, o rubor na face, um vacilar na fala. Partindo do id da situação, convida o cliente a dirigir-se também para o âmbito do sensível, quando Ihe pergunta como é para ele, como se sente. Note que o que está em jogo na experiência atual é a ação: "não sei", logo o terapeuta busca o verbo - aquele que indica a ação. Ele também indica a situação atual quando se envolve nela, lembrando ao cliente que ele está "aqui, diante de mim". A partir desse interesse, formula a pergunta dirigida à ação de não saber. 


\section{O id da situação, a forma motora e a signific-ação}

A noção de fé perceptiva a que nos referimos antes está baseada na noção merleau-pontyana de intercorporeidade. Está implicada com a mudança paradigmática que propõe Merleau-Ponty (2000) e que encaminha o viés desenvolvido neste trabalho: preconiza um conhecimento em estado nascente dado no a priori da correlação entre sujeito-objeto - só podendo ser acessado durante a experiência no mundo. Experiência ambígua que envolve a mim e ao outro, visível e invisível, como um ser bruto.

Dizer de um ser bruto, não significa dizer de uma confluência, de igualdade, coincidência plena. Entre nós há diferenças e a operação da reversibilidade me diz que o outro semelhante - que comunga da mesma carne, ou seja, do mesmo fundo de humanidade que eu - é, ao mesmo tempo, diferente. Essa diferença me lança no âmbito do invisível, do desconhecido, do novo, impulsionando um movimento de criação que me permita assimilar a diferença - ação do espírito selvagem.

O corpo, ao mesmo tempo coisa vista e vidente, sensível e sentiente, dirige $o$ ato criador. Através da experiência da reversibilidade tornase comunicante e assim se abre a possibilidade da intercorporeidade. Sentir com o outro, entrecruzar paisagens, a partir do exercício da fé perceptiva, uma experiência que cria um saber.

A experiência que se dá na fronteira de contato é um campo de presença - o lugar da experiência em estado bruto com o outro onde não há clareza e exatidão, mas um desdobramento temporal, um revezamento de figura e fundo, cada figura como a diferença, a novidade que brota do fundo e aponta para o futuro de possibilidades.

A noção de id da situação envolve esse campo de presença, as sensações que emergem, os excitamentos que são sentidos e que indicam a direção da ação futura. A função id do self, tal como proposto pela Gestalt-terapia, parte do corpo como um fundo de onde emerge a figura, o excitamento, o apetite, como uma percepção de início vaga, envolvendo sentimentos ainda incipientes entre organismo e ambiente. É uma função eminentemente corporal e sensória, está presente na consciência de modo difuso e é responsável por dar a direção da ação motora no campo.

Quando dizemos que a terapia busca a awareness da função id, estamos no âmbito dessa experiência ambígua e intercorporal, buscamos atingir uma camada de sentido bruto na minha relação com o outro, o id da situação. Propomos falar, então, de um fundo da experiência terapeuta-cliente, fundo bruto do qual emerge tudo, de onde parte a experiência que - vivida - produzirá novos significados que se agregarão ao fundo, encarregando-se de "re-formá-lo", 
servindo novamente de fundo para outras experiências, num movimento infinito de transformação da pessoa e do mundo. Esse fluxo, temporal, é o fluxo natural da experiência humana com o mundo. Experiência intercorporal, expressiva, produtora de significados que emanam da estrutura concreta da situação como forma ou configuração.

Podemos, assim, dizer que na psicoterapia se lida com um processo de ação significadora - signific-ação - que é da ordem da complexidade. A significação está no gesto expressivo, compreendido como uma condição do campo de presença: fundo histórico vivido em contato aqui e agora com o outro semelhante no mundo, ou seja, em situação, compondo uma significação bruta que envolve eu e outro em nossas dimensões visíveis e invisíveis. Tal significação assume uma forma que é o "objeto" da psicoterapia e que precisa ser acessada.

A Gestalt-terapia propõe um modo peculiar para acessar essa forma, um olhar referenciado em critérios estéticos, que se dirige ao sensível, à corporeidade. Quando a intervenção do terapeuta é dirigida para a sensação, mobiliza o cliente na mesma direção. A atenção à forma qualifica esteticamente o vivido e abre espaço para a geração de significados a partir da experiência da origem, abstraída das representações. Como no exemplo a seguir:

O cliente falava da noiva: "se ela continuar fazendo isso, vai ver, eu não sou pessoa com quem se faz esse tipo de coisa, se continuar vou mostrar a ela com quantos paus se faz uma canoa".

Fica muito tempo falando nesse tom, firme, voz alta, cenho franzido, gesticulando com as mãos, dedo indicador apontado, até que o terapeuta, atento ao cliente, ao que ele dizia, se dá conta de ele (terapeuta) está encolhido na cadeira, com o corpo tenso, com uma sensação de medo. Sabe que não tem medo do cliente e que aquela sensação era da situação.

Diz isso ao cliente: "Curioso... enquanto escuto você falar, me dou conta agora de que sinto medo"

O cliente faz uma expressão de grande surpresa e, em seguida, diz: “ É!! Eu não tenho necessidade de ameaçar a fulana!".

Ele se referia à noiva e o tema da ameaça já era seu velho conhecido, havia estado presente na terapia outras vezes. Era uma forma fixada de se proteger do mundo quando se sentia inseguro diante de opiniões diferentes das suas ou de comportamentos com os quais ele não concordava. Ele faz uma pausa e continua falando, agora avaliando se, de fato, o que ela vinha fazendo era apenas diferente do que ele desejava ou se era realmente uma coisa ofensiva. Conclui que não era.

A partir da intervenção terapêutica que se baseou no id da situação " sinto medo" - o cliente percebeu a forma fixada de funcionar "estou ameaçando para me defender". Passou, então, ao tema que 
correspondia à necessidade dominante: sua insegurança e necessidade de controlar pela ameaça para proteger-se da sensação de estar sendo agredido ou ameaçado quando alguém discorda dele.

Perls, Hefferline e Goodman descrevem o funcionamento neurótico como uma situação de emergência crônica de baixa intensidade, ou seja, uma situação crônica de desequilíbrio, que envolve uma sensação contínua de perigo e frustração. Na situação de emergência crônica de baixa intensidade não existe, de fato, na situação, uma ameaça. O perigo é uma distorção perceptiva, resultante da fixação em formas pré-determinadas.

A perspectiva fenomenológica refere-se a uma atividade intencional retencional que permite a construção de um fundo de experiências significantes que permanecem em nosso vivido. Entretanto, os vividos retidos não permanecem como conteúdo, mas como forma. Podemos falar, então, de um mundo cultural que continua de modo invisível, alheio à razão, "in-corporado" enquanto forma significante.

A fala fixa conteúdos que se tornam representações, personalidade, cultura. O vivido fixa formas sensoriais, motoras e da linguagem espontânea. A fala racionalizada traz o conteúdo representado na palavra, o gesto espontâneo traz a forma que não passa pela razão, mas que é significante, ou seja, permanece significando as experiências atuais.

Um dos principais objetivos do trabalho com a experiência na psicoterapia é justo aquele de proporcionar um espaço que ofereça ao indivíduo a oportunidade de perceber essa forma fixada, de reencontrar com aquilo que muitas vezes desconhece ou evita - mas que é inevitavelmente expresso na forma - e de retomar isso de modo criativo, transformando significados a partir da experiência.

Nas situações de emergência crônica, o objetivo da psicoterapia é, de acordo com Perls, Hefferline e Goodman (1997, p. 96),

provocar uma emergência segura concentrando-se na situação concreta [...] concentrar-se em uma emergência de alto grau existente, a qual o paciente pode realmente enfrentar e desse modo crescer.

Ao discutir o assunto, Robine (2003b, p.4) corrobora essa posição.

A psicoterapia é então concebida como uma situação de emergência oposta, que vai retomar inúmeros parâmetros da situação de emergência crônica, mas que, nesse novo contexto seguro e experimental, vai privar o paciente de suas respostas obsoletas para favorecer a criação de novas respostas ajustadas ao caráter novo da situação.

No exemplo anterior, ao compartilhar com o cliente o medo que se percebeu sentindo, o terapeuta partiu do id da situação. Um logos em estado bruto, um conhecimento intercorporal que orientou sua 
intervenção. Esta funcionou para o cliente como uma situação de emergência atual, um encontro com uma diferença real que se apresentava naquele lugar e naquele momento.

Consideramos que é nesse sentido que a Gestalt-terapia insiste na idéia de que o crescimento se dá quando há o encontro com a diferença, com a novidade. A terapia deve se concentrar na estrutura da situação concreta, na tarefa do ajustamento criativo diante da novidade e destacar a dimensão criativa da ação. Vislumbrar a possibilidade de enfrentamento da emergência aqui-agora significa entrar no âmbito da vivência de um "eu posso", no sentido merleaupontyano, dirigindo-se com o espírito selvagem para a ação que transforma e instaura significados.

Trabalhar com o id da situação é um modo de trabalho que se afasta completamente do paradigma intrapsíquico para considerar a estrutura, situação ou campo. Implica ainda mais o terapeuta, como no exemplo seguinte:

Terapeuta - "Noto que sua fala está interrompida, entrecortada..."

Cliente - "Sinto vontade de chorar e não consigo".

Terapeuta - "De que modo eu estou contribuindo para isso?"

Cliente - "Me olhando desse jeito, fixamente."

Terapeuta - "O que você quer fazer? Posso fazer alguma coisa em relação a isso?"

Cliente - "Pare de me olhar..."

O Terapeuta desvia o olhar, o cliente chora. Ele espera. O terapeuta diz: "Sinto-me longe de você, sinto uma sensação estranha estando aqui sem te olhar."

Cliente - "Também me sinto estranho... Mas aliviado por conseguir chorar. Também sinto uma sensação confusa, quero e não quero que você me olhe..."

O foco é na experiência, na awareness da função id - o sensorial que dá a direção do sentido para a intervenção: a fala do cliente que se apresenta de forma entrecortada é experimentada pelo terapeuta (id da situação) e dá a direção para sua ação motora (compartilhar sua percepção, dizendo ao cliente que percebe uma fala entrecortada). Essa fala do terapeuta ajuda o cliente a significar seu balbucio, buscando a awareness da função id no campo, (estou com vontade de chorar, mas não consigo fazer isso enquanto você me olha) e que se expressa na ação motora com o seu pedido (pare de me olhar um pouco, e o próprio choro).

O terapeuta se implica na situação quando, ao ouvir o cliente afirmar que não consegue chorar, pergunta como ele, terapeuta, está contribuindo para o que acontece ali, agora. Ora, se consideramos a situação terapêutica um campo de onde tudo emana, a presença do terapeuta está implicada ali de algum modo. Convidar o cliente a olhar para a contribuição do terapeuta o remete ao que está se apresentando na situação aqui e agora. 
A sessão poderia continuar de diversas maneiras. Uma delas seria estabelecer nesse momento um diálogo entre o lado que quer e o que não quer ser olhado pelo terapeuta. Outra seria escolher um dos lados e deixá-lo dirigir a cena. Ou simplesmente esperar.

O terapeuta espera.

Cliente - "Me acho ridículo chorando diante de você. (longa pausa). Sempre choro sozinho, quando estou perto de qualquer pessoa me sinto ridículo. (Pausa...) Lembro de quando era pequeno e meus avós brigavam muito. Minha mãe chorava e meu avô dizia que ela não tinha motivo. Ria dela, zombava, chamava ela de idiota, ridícula..."

O choro aumenta de intensidade, depois de um tempo fala da mãe, da pena que sente dela, que ao mesmo tempo se mistura com impaciência, também acha a mãe ridícula.

O terapeuta espera. Após uma grande pausa, o olha e pergunta: “E agora? Como é a sensação de ridículo aqui, comigo?"

O cliente teve acesso à forma interrompida e fixada (prender o choro na frente do outro). Esse acesso se deu através da experiência atual, ou seja, partindo do id da situação, uma direção foi dada, uma ação implementada e uma significação emergiu. O objetivo final é que ele, percebendo que esse é um novo contexto e que aquela estratégia não faz mais sentido hoje, percebendo que há suporte nesse contexto atual, implemente uma nova ação que crie um novo sentido, que reforme, que re-signifique.

O movimento criador é um movimento ativo na direção da significação ou da re-significação. De acordo com Chauí (1994), o espírito selvagem proposto por Merleau-Ponty é atividade nascida de uma força de querer e poder e de uma carência, uma lacuna sentida pelo sujeito como intenção de significar algo preciso e determinado "fazendo do trabalho para realizar a intenção significativa o próprio caminho para preencher $o$ seu vazio e determinar sua indeterminação, levando à expressão o que ainda e nunca havia sido expresso" (MERLEAU-PONTY, 1975, p.468).

Esse poder transformador e instaurador do novo decorre de uma capacidade exclusivamente humana: o trabalho - que se dá na ação a partir da significação da estrutura organismo-ambiente. MerleauPonty, lembramos, denomina trabalho a ação de produção de novas estruturas, transformação da natureza, por meio da produção de objetos de uso ou culturais que passam se interpor entre ele e a natureza. Por isso refere-se ao trabalho humano como uma "terceira dialética" (MERLEAU-PONTY, 1975, p. 197). Esse mesmo trabalho que possibilita a transformação da natureza, só o faz interpondo um terceiro elemento entre os dois termos. Esse terceiro elemento modifica a estrutura, cria uma nova realidade.

Para ele, aquilo que é mais característico da ordem humana é esse poder criador, a capacidade de ultrapassar as estruturas já criadas para criar outras. O trabalho não é uma atividade da razão, 
representacional, mas atividade que envolve um engajamento corporal estabelecendo, numa perspectiva temporal, relação com o ausente, com a possibilidade de ultrapassar algo dado, a "apropriação de um espaço e um tempo indefinidos" (MERLEAU-PONTY, 1975, p.210). Uma síntese prática realizada pelo corpo na percepção que conduz ao novo, a partir de uma experiência motora - praktognosia e de uma experiência expressiva que - lembramos - sempre visa à tarefa presente na situação. Perls, Hefferline e Goodman (1997, p.209) descrevem o processo de ajustamento criativo de modo semelhante, ressaltando o caráter de descoberta e invenção do self:

\begin{abstract}
A partir do princípio e durante todo o processo, ao ser excitado por uma novidade, o self dissolve o que está dado (tanto no ambiente quanto no corpo e em seus hábitos), transformando-o em possibilidades e, a partir destes, cria uma realidade. A realidade é uma passagem do passado para o futuro: isto é o que existe, e é disso que o self tem consciência, é isso que descobre e inventa.
\end{abstract}

No futuro está o desconhecido e o novo. Correr o risco de enfrentá-lo não prescinde de fé, de crença no poder de criar o novo, de falar uma fala falante (MERLEAU-PONTY, 1994). Assim, a fala enquanto um gesto corporal tem um sentido de criação, ela é trabalho. Quando alguém produz uma fala falante, nova, impensada, quando diz aquilo que não foi dito, está criando. O homem cria objetos de uso, artefatos e palavras que vão se interpor entre ele e o mundo ((MERLEAU-PONTY, 1994), coloca elementos novos no mundo, dissemos antes. O movimento criador instaura cultura. No entanto, se alguém fica aprisionado na fala que já falou - fala falada - está neurótico, porque criou algo que o escraviza. Nesse sentido, a personalidade pode escravizar.

Consideramos que o encontro terapêutico que tem como perspectiva conduzir ambos, terapeuta e cliente ao âmbito do desconhecido na busca da experimentação de um poder criativo faz surgir uma criação, uma obra. Essa obra não tem autoria, tampouco é acabada. O olhar para ela se aproxima da experiência estética, uma vez que não é um olhar que busca uma compreensão intelectual, mas um encontro com as qualidades afetivas que a obra suscita - qualidades que são reveladas na experiência com a obra, ao mesmo tempo em que a constituem como um objeto estético. Esse olhar é um tipo de percepção definido por Dufrenne (2004, p. 80) como percepção estética:

aquela que só quer ser percepção, sem se deixar seduzir pela imaginação que convida a vaguear em torno do objeto presente, ou pelo intelecto que, para dominar o objeto, procura reduzi-lo a determinações conceituais. 
Quando a Gestalt-terapia propõe ficar com a experiência do cliente, ela assume uma posição ética e corajosa: ao mesmo tempo em que o terapeuta deseja que o cliente vivencie sua espontaneidade e se abra criativamente para a novidade e o desconhecido, ele próprio abre mão do "controle" da situação, se lançando também para o âmbito do desconhecido.

Penso que sua proposta metodológica se manteve sempre coerente. Não podemos fazer Gestalt-terapia de modo genuíno se evitamos (neuroticamente) o trabalho com a experiência. Sem dúvida, é muito mais fácil e seguro interpretar, ficar com a experiência do outro sem nos implicar, considerá-la de fato do outro, controlar a situação. Entretanto, o desafio aqui é enfrentar a experiência e confiar em nosso poder agressivo de ajustamento criativo na situação junto com o outro. A agressão visa quebrar a estrutura no nível simbólico da significação, se libertar da cultura instituída que aprisiona. Para isso, é necessário engajamento, corporeidade, de ambos, terapeuta e cliente.

Partindo das idéias aqui discutidas, sintetizadas nas dimensões corpo, ato e signific-ação propomos denominar a experiência na clínica da Gestalt-terapia um processo de experiment-ação. Experimentar a ação. A ação de experimentar. Sua origem etimológica envolve a palavra experientia, que significa prova, ensaio, tentativa e o radical peri, do latim, periculum, que significa perigo e risco. Uma ação que experimenta o risco. Arriscar-se, aventurar-se, atirar-se. Sinônimos. Verbos indicadores de ações que mobilizam o ser rumo ao desconhecido, ao novo, ao estranho. A sair dos limites daquilo que está circunscrito ou limitado pelo alcance de nossa visão. O que está circunscrito pode ser o corpo, a forma, o significado, o espaço, a existência.

A experiment-ação é proposta de resgate da corporeidade, veículo para a expressão, para a emergência de uma ação criativa produtora de significados. Construir significados para a existência pelo fenômeno que brota da experiência talvez seja o sentido mais profundo da experiment-ação, tal como propomos aqui.

Na neurose, o "descobrir e inventar" estão prejudicados, esquecidos ou perdidos. A orientação e a confiança no futuro, o sentido temporal da possibilidade está substituído por uma fixação no passado. A excitação que movimenta para o inventivo está anestesiada, o corpo age mecanicamente, dirigido pela vontade desligada do desejo e da situação. A repetição substitui a invenção.

A experiment-ação proporciona um estado de invenção que nos leva além do que está dado. Esse estado define a aventura da transgressão, tal como compreendemos.

Perls, Hefferline e Goodman nos lembram que nessa aventura, estamos sujeitos a nos deparar com novas descobertas-e-invenções derivadas da criação. Nos advertem de que muitas vezes, a novidade 
está em desacordo com o que achamos ideal e com o que seria coerente com nosso senso de eu - personalidade. Mas reafirmam a confiança na possibilidade humana transgressora: "no momento do interesse, a escolha é ousada e revolucionária", o selvagem nos movimenta e o risco da aventura pode ser assumido.

Nesse caso, temos de nos arriscar a sermos absurdos ou solitários.

\section{Referências Bibliográficas}

ALVIM, M. B. Experiência estética e corporeidade. Estudos e pesquisas em psicologia, UERJ, Rio de Janeiro, v.7 n.1, primeiro semestre, 2007a.

. Ato artístico e ato psicoterápico como Experiment-ação: diálogos entre a fenomenologia de Merleau-Ponty, a arte de Lygia Clark e a Gestalt-terapia. 2007b. 374 f. Tese (Doutorado em Psicologia) - Instituto de Psicologia, Universidade de Brasília, Brasília. CHAUÍ, M. Merleau-Ponty: Obra de arte e filosofia. In: NOVAES, A. (Org. ). Artepensamento. São Paulo: Cia das Letras, 1994.

DUFRENNE, M. Estética e Filosofia. São Paulo: Editora Perspectiva, 2004.

GOLDSTEIN, K. The Organism: a holistic approach to biology derived frompathological data in man. New York: Zone Books, 2000.

GRANZOTTO, R.L. Gênese e construção de uma "Filosofia da Gestalt" na Gestalt-terapia. 2005. 131 f. Dissertação (Mestrado em Filosofia) - Departamento de Filosofia, Universidade Federal de Santa Catarina, Florianópolis.

LEWIN, K. Princípios de psicologia topológica. São Paulo: Cultrix, 1973.

MERLEAU-PONTY, M. A estrutura do comportamento. Belo Horizonte: Ed. Interlivros, 1975.

$\overline{1} \overline{9} \overline{9} \overline{.}$

Fenomenologia da percepção. São Paulo: Martins Fontes,

$\overline{2} \overline{0} \overline{0}$.

O visível e o invisível. São Paulo: Editora Perspectiva,

MILLER, M. V. The aesthetics of commitment: what gestalt therapists can learn from Cezanne and Miles Davis. The Gestalt J ournal,New York, Vol. 25, n. 1, p. 109-122, Spring, 2002.

PERLS, F. Ego, Fome e Agressão: uma revisão da teoria e do método de Freud. São Paulo: Summus, 2002.

PERLS, F.; HEFFERLINE, R.; GOODMAN, P. Gestalt-terapia.São Paulo: Summus, 1997.

PERLS, L. Living at the boundary. New York: The Gestalt Journal Press, 1992. 
ROBINE, J. M. Intentionality in Flesh and Blood: Toward a Psychopathology of Fore-Contacting. International Gestalt Journal, New York, v. 26, n.2, $2003 a$.

. Do campo à situação. Tradução Selma Ciornai. Revista de Gestalt, Instituto Sedes Sapiens, São Paulo, n.12, 2003b.

- A Gestalt-terapia terá a ousadia de desenvolver seu

paradigma pós-moderno? Tradução Mônica B. Alvim. Estudos e

Pesquisas em Psicologia,UERJ, Rio de Janeiro,v. 5, n. 1, primeiro semestre, 2005.

STOEHR, T. Aqui, ahora y lo que viene: Paul Goodman y la Psicoterapia Gestalt em tiempos de crisis mundial. Santiago: Editorial Cuatro Vientos, 1999.

\section{Endereço para correspondência}

Mônica Botelho Alvim

Universidade Federal do Rio de Janeiro UFRJ, Psicologia, Avenida Pasteur, 250,

Pavilhão Nilton Campos, CEP 22290-240, Praia Vermelha, Rio de Janeiro-RJ, Brasil

Endereço eletrônico: mbalvim@gmail.com

J orge Ponciano Ribeiro

Campus Universitário Darcy Ribeiro, Instituto Central de Ciências, Pós graduação em Psicologia, Ala Sul, CEP 70910-900, Asa Norte, Brasília-DF, Brasil

Endereço eletrônico: jorgeponcianoribeiro@yahoo.com.br

Recebido em: 24/04/2008

Aceito para publicação em: 01/04/2009

Editor responsável: Eleonôra Torres Prestrelo

Notas

* Doutora em Psicologia pela Universidade de Brasília/UnB.

** Doutor em Psicologia. 